\title{
Design of a strategy Supply Chain Aligned with the strategy of the company
}

\author{
Jaouad KAZMANE ${ }^{1}$, Abdelali ENNADI ${ }^{2}$, Anas $\mathrm{CHAFI}^{3}$, Ikram TAJRI ${ }^{4}$ \\ Industrial Engineering Department, Laboratory of Industrial Technology, \\ Faculty of Sciences and Technologies, Fes, Morocco. \\ ${ }^{1}$ kazmane10@yahoo.fr \\ ennadi.abdelali@yahoo.fr \\ 3anaschafi@gmail.com \\ 4tajriikram@gmail.com
}

\begin{abstract}
In a highly competitive environment, cost reduction and optimization of the supply chain are more than ever a strategic issue for companies. In this context, the good alignment of the supply chain with the corporate strategy is essential to ensure a high level of performance. The design or the choice of a Supply Chain strategy is determined at the same time by the objectives of the company, but also by the taking into consideration of the environment where the supply chain is inserted. Then, according to the specifications and the request of the customers, the strategies converse between the operational excellence or the customer closeness.
\end{abstract}

This research serves as a model or a theoretical framework supported by experiments through surveys in companies of the United States and Canada for the design of Supply Chain strategies aligned with the strategy of the company.

Keyword-Strategy, Supply chain, Company, operational excellence, customer closeness

\section{INTRODUCTION}

The goal of this work is to propose a sub model of design of the Supply Chain strategy Aligned with the strategy of the company. For this we have based on the Investigation [1], the works realized by the authors [2], [3], [4] - [5] to position:

- The strategy of the company;

- Supply chain environment;

- The design of supply chain strategies;

- Supply chain capabilities;

- The measurement of supply-side and demand-side performance.

The design or the choice of' a Supply Chain strategy is determined at the same time by the objectives of the company that will be transformed into corporate strategies, But also by the taking into consideration of the environment where the supply chain is inserted. Then, according to customers' specifications and demands, the strategies evolve between operational excellence or customer closeness. Each strategy uses tools and concepts, which allow the supply chain to configure and install in sequences the supply chain capabilities, which will increase the performance of the supply chain. The results of these studies make it possible to approach or achieve the objectives set by the company.

In this context, the proper alignment of the supply chain with the company strategy is essential to ensure a high level of performance of the company.

Several authors [1] [2], [3], [4] - [5] have developed several models concerning the formulation of supply chain strategies. Unfortunately, these attempts have not given enough attention to the connections and combinations of key factors throughout the value chain, Nor to their alignment with the competitive framework of their field of activity. We conducted an analysis of the theories the more widely recognized and the case studies on the strategies supply chain. Our analysis identified a set of common models that reveal the key drivers of supply chain strategies. And explain how these can be aligned in a strategy coherent with the company's strategy (Figure 1).

\section{THE STRATEGY OF THE COMPANY}

Strategy of the company: Refers to the set of resource allocation choices that define the scope of an organization's activities to ensure its profitability, its development and / or its durability. It corresponds to the development axes chosen for the company and is realized through a system of objectives and an economic model (or a value chain) driven by a complex decision-making process.

According to Michael E. Porter, it is possible to distinguish the following generic strategies at the level of each of the fields of ac strategic activity: 
- The strategies of domination by the costs, which consist in offering the same offer as the competitors, but in a lower price: This is the approach claimed by Hyundai in the automobile or Leclerc in in the large distribution. For this, we often supports on the effect of experience, which allows to reduce the marginal cost by an increase in the cumulative volume. A pricing strategy that is based on this principle is called strategy of volume.

- The strategies of differentiation, That we distinguish between differentiation upward or sophistication (Offering a more elaborate and more expensive offer than the competitors, but sold even more expensive: BMW, Apple, Starbucks, Häagen-Dazs,..) And downward differentiation or purification (Offer a less developed and much less expensive than the competitors but sold less expensive: easyJet, Ryanair, Lidl, Dacia, Bic, H\&M,...). In both cases, the aim is to create a positive differential between the cost differential and the price differential in relation to the reference offer: Either we increases the price more than the cost (differentiation towards the top), either we reduced the cost more than the price (differentiation toward the bottom).

- The strategy of focusing: We focus on a niche of market. For this, it is necessary that the market is small enough not to attract big competitors and require sufficiently specific investments to discourage other small competitors. The main trap of a niche is to make it grow.

In the development of our sub model" design of a strategy Supply Chain Aligned with the strategy of the company, Fig. 1, We are going to be more interested in strategies that have in relation with the supply chain.

\section{SUPPLY CHAIN ENVIRONMENT}

The supply chain environment refers to the interaction between the industry framework, the competitive framework and existing supply chain capabilities. In effect, the framework of industry also presents the reactions between suppliers, customers, technological developments and economic factors. In this framework, the four main factors affecting the design of the supply chain, all linked between them are:

1) The variation of the demand or the profile of the demand, Exercise an influence on the stability and the coherence of the workload of the assets of manufacturing, and therefore it considers itself among the main factors in the efficiency of production and the determination of the cost of the final product.

2) The market mediation fee, as defined by [5], the costs associated to the imbalance in the supply and demand. The examples include discounts of products to indemnify the oversupply and the missed sales when the request exceeds the offer. These costs, which reflect the unstable and fragile balance between lost sales and product obsolescence, result from consequences of the degree of predictability of the request.

3) Product life cycle, which is continuously shorten in response to the speed of the change of the technology, The mode and the trends of consumer product which affects the predictability of the request and the costs of mediation of the market. Consequently, it pushes companies to increase the speed of product development and continually renew their product portfolios.

4) Relevance of asset cost to total cost becomes critical in industrial sectors where corporate profits are strongly correlated with the asset utilization rate. Companies adapting this profile must ensure a high utilization rate, often to the detriment of the levels of service and the Working Capital. . In the industries where the relevance of the cost of assets is low, companies can choose strategies which emphasize the responsiveness. In these cases, the rate of use of the assets is located between high and low, but unexpected demand responsiveness is high, by increasing the customer satisfaction and to reduce the costs of market mediation.

The competitive framework is the second element of the supply chain environment which affects the proposal of the unique value and which requires a clear understanding of the competitive position of the organization in terms of its supply chain. A good approach, it is the concept of "The qualified Commands" and "Commands earned" described in 1995 by Alex and Terry Hill. These concepts define, respectively, the minimum requirements to be considered as a relevant option by customers, and the aspects of performance that best differentiate the company from its competitors and thus help winning customer orders. The alignment and the connection between the competitive positioning of an organization and the process of the supply chain are governed by the decision-making process and are driven by the supply chain management. This orientation is the most important factor to ensure the consistency between the execution of the supply chain and the proposal for a single value of a business. Yet, it can also be an area where organizations are more likely to fail. These failures are mainly due to a standard management approach that focuses on performance-oriented performance indicators independently of the competitive positioning defined by the organization.

The existing capabilities of the supply chain are the basic components of the strategy supply chain and a source of competitive advantage for the success of the company. It provides guidance that ensures appropriate connection and combination in supply chain activities that fall under supply, production and delivery categories. However, the absolute level of existing supply chain capabilities of the company offers the ability to meet an 
acceptable minimum level of customer requirements to be of the qualified order or to be accredited as acceptable suppliers.

\section{IV.SUPPLY CHAIN STRATEGY DESIGN}

The literature of existing supply chain strategies suggests that the customized supply chain shapes supply chain capabilities and value-added services to the specific needs of customers. Indeed, the supply chain strategy defines the connections and combinations of activities and functions throughout supply chain, to fulfill the value proposition of the company to the customer in a market.

After the projection of the strategies of the company, the understanding and the framing of the environment of the supply chain, the design of the supply chain strategy is generates from the careful determination of the specific needs of customers. This determination guides the selection between the type of supply chain strategy, i.e. a strategy of operational excellence or a strategy of reconciliation or closeness of the customer. On the other hand, the best practices of the strategies supply chain of operational excellence or from the request, customer closeness should be apparent on both the capabilities that in the performance of the supply chain of companies practicing these strategies. Again, the minimum threshold standard for supply and demand can be qualified as a supplier potential. Operational excellence is based on tools and concepts such as Just in Time and Lean supply chain, while the closeness of the customer uses the customization, the logistics segment and agility.

The strategy of operational excellence can support business strategies through cost leadership, such as reducing total cost, efficient and reliable procurement, basic service, and differentiation as a single service and added value. According to [1], companies pursuing operational excellence are tireless in the search for the ways to reduce costs, eliminate intermediate steps non-producing added value, reduction of the transactions and other frictions of the costs. The Operational excellence can be supported by supply chain capabilities such as low logistics costs, distribution coverage and availability, reliability, standardization of operations, timely deliveries and timeliness. Finally the goal of operational excellence is generally to lead an industry in price, the reliability, the convenience and speed.

Using Just-In-Time (JIT) in the operational excellence strategy focuses on delivering timely and accurate (ie, time variability is low). This can reduce the buffer stocks and safety stocks. JIT may also involve more frequent deliveries of smaller shipments, which can increase inventory throughput or velocity. In turn, this lower intransit stock and cycle stocks.

Other contemporary logistics operations that can facilitate JIT and thereby also reduce stocks include crossdock operations, synchronizing and sequencing transportation with production, delivering commodities to exact points on the production line using flexible transportation equipment and containers, in-transit acceleration and deceleration to regulate the flows, and direct delivery.

The implementation of the Lean supply chain reduces all types of waste, errors, unnecessary assets, and cycle times by continuously seeking perfection and operational efficiencies throughout the supply chain network. Types of logistics-related waste that can add cost but no value include waiting, rectification of mistakes, excess processing, unnecessary warehousing, extra handling, excess transport and terminals, and excess stock. Innovative logistical solutions may involve outsourcing, using postponement strategies, redesigning process, optimally locating facilities, reducing or redeploying network assets, and having resident suppliers' production lines.

On the other hand, the supply chain strategy, the customer closeness means selling the customer not just a product or service, but rather total customer satisfaction through augmented solutions that include ongoing help, high levels of support, and interactive advisory service. Firms following this strategic approach increasingly become experts on their customers' businesses and continuously elevate the relationships. This may mean advancing through levels of customer service, to customer satisfaction, to customer success.

The strategy customer closeness can support the business strategies of the company through the differentiation by high levels of customer service, the value added and proactive quality, collaborative communication and customer interactions. The customer closeness strategy is sometimes mentioned as a center of demand management in the literature of the strategy supply chain. According to [1] the supply chain strategy involving customer closeness allows the production of capabilities such as responsiveness to key customers, special value-added customer services, customization and innovative solutions, flexibility, proactive quality and communications, intermodal transfers, and again dependability. The customer closeness also requires long-term interactive relationships with customers, suppliers and the partners of the company.

\section{THE SUPPLY CHAIN CAPABILITES}

The result of the design of strategies supply chain according to the sub-model is the configuration and the sequencing the capabilities of the strategies supply chain and of the added-value services to the specific needs of the customers. For customers this means providing with efficiency and in a reliable manner of products and services at competitive prices and with a minimum of difficulties and inconvenience. This reflects the 
minimization of total cost to the customers, not only because of the drop in the price, but also because of the reduction of the costs of the partners of the execution of optimal order and subsequently the compression of the parameter of the time of the supply chain. To this title. The supply Chain capabilities can focus on using the total cost of the supply chain as a marketing weapon also to retain existing customers as well, to attract new customers.

For example, according to the survey carried out by [1], Table I. shows the seven best supply chain capabilities, which can be considered as core competencies for the success of the supply chain and consequently the performance of the supply chain and the entire enterprise;

TABLE.I Importance of Supply Chain Capabilities for the success of the company [1]

\begin{tabular}{|c|c|c|c|c|}
\hline Supply chain Capabilities & Côte Supply chain & Score moyen & rang & Importance \\
\hline Customer service & \multirow{2}{*}{ Demand side } & 1,11 & 1 & \multirow[t]{2}{*}{ 1st rank } \\
\hline Quality & & 1,16 & 2 & \\
\hline Information systems support & & 1,57 & 3 & \multirow[t]{2}{*}{ in the middle } \\
\hline Distribution flexibility & & 1,78 & 4 & \\
\hline Low logistics cost & \multirow{3}{*}{ Supply side } & 2,04 & 5 & \multirow{3}{*}{$\begin{array}{l}\text { Less } \\
\text { important }\end{array}$} \\
\hline Productivity & & 2,37 & 6 & \\
\hline Delivery speed & & 2,45 & 7 & \\
\hline $1:$ important & $5:$ unimportant & & & \\
\hline
\end{tabular}

Customer service and quality rank first and second in importance, respectively. Information support and distribution flexibility are in the middle, while low logistics cost, productivity, and delivery speed rank lower in importance. Thus, in general, demand-side capabilities of customer service and quality tend to be ranked more important for supply chain success than supply-side capabilities such as cost, productivity, and delivery speed. However, the absolute level of scores possibly implies that firms must meet minimum acceptable levels on all of these capabilities to be order-qualified or to be certified as acceptable suppliers.

\section{A. Relationships between supply chain capabilities and firm excellence}

The Table II. Visualizes the relationship between Supply Chain capabilities and the excellence of the company this correlation between performances on 26 different supply chain capabilities, with an index of excellence of the company:

Demand-side capabilities consist of customer service and quality variables. As shown in TABLE II. Six of the seven customer service capabilities are positively and significantly related to firm excellence. Order flexibility followed by value-added services shown the strongest relationships to the firm excellence index. For the quality category, the four proactive capabilities (i.e., "do it right the first time") are significantly related to the firm excellence index, while the three reactive capabilities are not. The four proactive capabilities in decreasing order of statistical strength include delivery dependability, order fill consistency, avoiding disruptions in supply, and problem avoidance. Similarly, advanced customer notification of problems is also positively related to firm excellence. However, the reactive quality capabilities do not achieve statistical significance with firm excellence and include problem and complaint resolution, product substitution, and product recall.

For supply-side capabilities, low logistics cost and standardization of operations are marginally yet significantly related to firm excellence. In turn, none of the five distribution capabilities nor the two logistical speed capabilities are significantly related to firm excellence.

In summary, the more demand-oriented capabilities of customer services and quality are most strongly related to firm excellence. However, for the quality category, it appears to be primarily the proactive capabilities that are significantly related to firm excellence, rather than reactive quality capabilities or problem recovery. In turn, supply-side capabilities of low logistics cost and productivity are less strongly related to firm excellence, with distribution and logistics speed are not related at all in this analysis.

\section{B. The benchmarking analysis of the capabilities of the Supply Chain}

For managerial orientation, TABLE III. Provides a different but benchmarking analysis. It compares the capacity performance of the top third excellence index firms with the bottom third. The top third benchmarked firms are the best of the best benchmark. From a managerial perspective, what is important and of prime interest to management is benchmarking against the best of the best firms, rather than against those of moderate success or those "stuck in the middle". 
TABLE II Pearson Product-Moment correlations between Supply Chain capabilities and firm excellence [1]

\begin{tabular}{|c|c|c|}
\hline Supply Chain Capabilities $^{\mathrm{a}}$ & $\begin{array}{l}\text { Correlation with } \\
\text { Excellence Index }\end{array}$ & p-value \\
\hline \multicolumn{3}{|l|}{ A-Customer Service } \\
\hline 1-Responsiveness to key Customers & $0,214^{\mathrm{d}}$ & 0,035 \\
\hline 2-Value-added services & $0,289^{\mathrm{c}}$ & 0,005 \\
\hline 3-Logistics service différentiation & $0,159^{\mathrm{d}}$ & 0,088 \\
\hline 4-Customer service flexibility & $0,247^{\mathrm{c}}$ & 0,014 \\
\hline 5-Order flexibility & $0,397^{\mathrm{b}}$ & 0,001 \\
\hline 6-Customization during logistics & $0,193^{\mathrm{d}}$ & 0,059 \\
\hline 7-Innovative solutions & 0,8 & 0,247 \\
\hline \multicolumn{3}{|l|}{ B-Quality } \\
\hline 1-Delivery dependability (proactive) & $0,268^{\mathrm{b}}$ & 0,001 \\
\hline 2-Order fill consistency (proactive) & $0,218^{\mathrm{d}}$ & 0,029 \\
\hline 3-Problem avoidance (proactive) & $0,155^{\mathrm{d}}$ & 0,091 \\
\hline 4-Avoid disruption in supply (proactive) & $0,178^{\mathrm{d}}$ & 0,062 \\
\hline 5-Problem and complaint resolution (reactive) & 0,14 & 0,113 \\
\hline 6-Product substitution (reactive) & 0,88 & 0,226 \\
\hline 7-Product recall (reactive) & 0,107 & 0,181 \\
\hline \multicolumn{3}{|l|}{ C-Information } \\
\hline 1-Advanced problem notification (proactive) & $0,186^{\mathrm{d}}$ & 0,053 \\
\hline 2-Advanced shipment notification (proactive) & 0,099 & 0,197 \\
\hline \multicolumn{3}{|l|}{ D- Logistics cost and productivity } \\
\hline 1- Low logistics cost & $0,179^{\mathrm{d}}$ & 0,068 \\
\hline 2- Standardization of operations & $0,151 \mathrm{~d}$ & 0,099 \\
\hline 3- Simplification of operations & 0,053 & 0,325 \\
\hline \multicolumn{3}{|l|}{ E- Distribution } \\
\hline 1- Widespread distribution coverage & 0,127 & 0,139 \\
\hline 2- Selective distribution coverage & 0,12 & 0,155 \\
\hline 3-Location flexibility & 0,106 & 0,185 \\
\hline 4- Delivery time flexibility & 0,013 & 0,455 \\
\hline 5- Reverse logistics timing & 0,129 & 0,153 \\
\hline \multicolumn{3}{|l|}{ F- Logistical Speed } \\
\hline 1- Delivery speed & 0,122 & 0,147 \\
\hline 2- Expedited delivery & 0,144 & 0,108 \\
\hline
\end{tabular}

The benchmarking results in TABLE III. Are analogous to TABLE II. And provide additional corroboration of results for management. In general, the more demand side capabilities in the categories of customer service, proactive quality, and advance information to customers again more successfully distinguish top third excellence index firms than do reactive quality or supply side capabilities. Specifically, proactive information capabilities of bath advance notification of problems and advance shipment information now also sighificantly distinguish top third firms. For supply side capabilities, standardization still does. But low logistics cost does not, significantly differentiate between the two group in this particular analysis.

\section{PERFORMANCE MEASUREMENT}

Eventually supply chain strategies and supporting capabilities devolve into performance outcomes as represented in Sub model Fig 1. At the performance outcome level, TABLE IV. And TABLE V. evaluate demand side and supply side performance measures.

\section{A. Demand side}

TABLE IV. Benchmarks the demand side performance measurement practices of top third firms versus the bottom third on customer service and quality performance measures. Availability of performance information 
and its managerial importance are evaluated against these top firms. TABLE IV. Shows that the first four customer service performance measures and the first six quality measures statistically differentiate top third firms from the bottom third on either information availability or importance. For example, top third excellence index firms attribute both greater importance and information availability to fill rate, complete order, and credit claims. These measures are available to over $90 \%$ of top third firms and be characterized as basic performance measures. In contrast, more esoteric measures such as backorder performance, complaints from the salesforce, and response time to customer inquiries do not distinguish top third from bottom third firms.

TABLE III. Supply chain capabilies of top third excellence index firms versus bottom third [1]

\begin{tabular}{|c|c|c|}
\hline \multirow{2}{*}{$\begin{array}{l}\text { Supply chain capabilities: }^{\text {a }} \\
\text { A. Customer service }\end{array}$} & \multicolumn{2}{|c|}{ Mean Performance } \\
\hline & Top third & Bottom third \\
\hline 1-Responsiveness to key customers & $4,07 \mathrm{~d}$ & 3,61 \\
\hline 2-Value-added services & $3,82 \mathrm{c}$ & 3,33 \\
\hline 3-Logistics service differentiation & 3,59 & 3,28 \\
\hline 4-Customer services flexibility & 3,76 & 3,5 \\
\hline 5-Order flexibility & $4,06 \mathrm{~b}$ & 3,12 \\
\hline 6-Customization during logistics & $3,33 \mathrm{c}$ & 2,28 \\
\hline 7-Innovative solutions & $4,00 \mathrm{~d}$ & 3,61 \\
\hline \multicolumn{3}{|l|}{ B-Quality } \\
\hline 1-Delivery dependability (proactive) & $4,35 \mathrm{~b}$ & 3,78 \\
\hline 2-Order fill consistency (proactive) & 4,24 & 4,17 \\
\hline 3-Problem avoidance (proactive) & $3,82 \mathrm{~d}$ & 3,44 \\
\hline 4-Avoid disruption in supply (proactive) & $3,94 d$ & 3,5 \\
\hline 5-Problem and complaint resolution (reactive) & 4,06 & 3,78 \\
\hline 6-Product substitution (reactive) & 3,59 & 3,33 \\
\hline 7-Product recall (reactive) & 3,94 & 4,06 \\
\hline \multicolumn{3}{|l|}{ C-Information } \\
\hline 1-Advanced problem notification (proactive) & $3,65 \mathrm{c}$ & 3,06 \\
\hline 2-Advanced shipment notification (proactive) & $3,35 \mathrm{~d}$ & 2,94 \\
\hline \multicolumn{3}{|l|}{ Logistics cost and productivity } \\
\hline 1- Low logistics cost & 4,17 & 3,83 \\
\hline 2- Standardization of operations & $4,00 \mathrm{c}$ & 3,29 \\
\hline 3- Simplification of operations & 3,41 & 3,18 \\
\hline \multicolumn{3}{|l|}{ Distribution } \\
\hline 1- Widespread distribution coverage & 4,24 & 4,00 \\
\hline 2- Selective distribution coverage & $3,82 \mathrm{c}$ & 3,12 \\
\hline 3-Location flexibility & 3,65 & 3,35 \\
\hline 4- Delivery time flexibility & 3,94 & 3,94 \\
\hline 5- Reverse logistics timing & 3,53 & 3,43 \\
\hline \multicolumn{3}{|l|}{ F- Logistical Speed } \\
\hline 1- Delivery speed & $3,71 \mathrm{c}$ & 3,06 \\
\hline 2- Expedited delivery & 4,00 & 3,94 \\
\hline \multicolumn{3}{|c|}{$\begin{array}{l}\text { a Scale }: 1=\text { performance worse than competitors ; } 5=\text { performance better than } \\
\text { competitors } \\
\text { b p } \leq 0,001 ; \mathrm{c} \mathrm{p} \leq 0,01 ; \mathrm{d} \mathrm{p} \leq 0,1\end{array}$} \\
\hline
\end{tabular}

Some customer service and quality measures in TABLE IV. Appear to be minimum hurdles in that they are available a to very high percentage of bottom third firms. These include on time deliveries, number of customer return, delivery consistency, and damage frequency. Apparently, these basic attributes are order qualifiers to be even considered as a potential supplier or partner. Thus, they would not significantly differentiate between groups.

The far right column of TABLE IV. Also shows the relative importance rankings given by top third firms to measures of customer service and quality, respectively. In general, the most important rankings tend to be for 
basic, proactive, positive, and total performance measures. Specifically, the top four out of eleven customer service measures in descending order of importance are stockouts, fill rates, on time delivery, and overall customer satisfaction. These basic and primarily proactive performance attributes reflect whether the firm's customers got what they wanted, where and when they wanted it, and in the condition they wanted it. In turn, the top four quality measures out of nine, in decreasing order of importance to top third firms are picking and shipping accuracy, overall reliability, delivery consistency, and invoicing accuracy. These quality attributes are also proactive measures that represent positive performance. In contrast, the less important quality variables are primarily reactive and negative performance measures and include shipping errors, number of customer returns, number of credit claims, and damage frequency. It should also be noted that both overall customer satisfaction and overall reliability are total performance measures that are ranked very important by best in class firms.

In summary, the customer service and quality performance rankings show that basic, proactive, positive, and total performance measures are deemed most important by benchmarked top third firms. However, it is also interesting to compare importance rankings of top third firms with their information availability rankings in TABLE IV. Specifically, the least important quality ranked variables are some of the most highly tracked quality measures. In terms of information availability, these quality rankings include number of customer returns, number of credit claims, shipping errors, and damage frequency. Thus, despite being less important, these reactive quality measures are tracked at a relatively high level by the best in class firms.

TABLE.IV Availability and importance of demand side performance measures for top third excellence index firms versus bottom thir [1]

\begin{tabular}{|l|l|l|l|l|l|l|}
\hline \multirow{2}{*}{ Performance Measures : } & \multicolumn{3}{|l|}{ Percent having information available } & \multicolumn{3}{l|}{ Average importance rating a } \\
\cline { 2 - 7 } & $\begin{array}{l}\text { Top Tiers } \\
\text { [\%] }\end{array}$ & $\begin{array}{l}\text { Tiers } \\
\text { inférieur [\%] }\end{array}$ & $\begin{array}{l}\text { Top Tiers } \\
\text { rang }\end{array}$ & $\begin{array}{l}\text { Top } \\
\text { Tiers }\end{array}$ & $\begin{array}{l}\text { Tiers } \\
\text { inférieur }\end{array}$ & $\begin{array}{l}\text { Top Tiers } \\
\text { rang }\end{array}$ \\
\hline $\begin{array}{l}\text { A-Customer services } \\
\text { measures }\end{array}$ & $96,9 \mathrm{~b}$ & 61,1 & 1 & $4,50 \mathrm{~b}$ & 3,73 & 2 \\
\hline 1-Fill rate & $93,8 \mathrm{~d}$ & 77,8 & 2 & 4,52 & 4,19 & 1 \\
\hline 2-Stockouts & $90,6 \mathrm{~d}$ & 72,2 & 4 & 4,16 & 3,82 & 7 \\
\hline 3-Cycle time & C0,0b & 52,9 & 5 & $4,26 \mathrm{c}$ & 3,71 & 6 \\
\hline 4-Complete orders & 93,6 & 89,5 & 3 & 4,43 & 4,47 & 3 \\
\hline 5-On time deliveries & 79,3 & 76,5 & 6 & 3,92 & 3,8 & 9 \\
\hline 6-Backorders & 71,0 & 79,0 & 7 & 4,35 & 4,28 & 5 \\
\hline 7-Customer complaints & 58,1 & 55,6 & 8 & 4,39 & 4,41 & 4 \\
\hline 8-Overall satisfaction & 42,9 & 33,3 & 9 & 3,94 & 3,64 & 8 \\
\hline 9-Sales force complaintes & 41,9 & 29,4 & 10 & 3,73 & 3,93 & 11 \\
\hline 10-Response time to inquiries & 32,3 & 22,2 & 11 & 3,8 & 4,00 & 10 \\
\hline 11-Response accuracy & & & & 4,18 & & \\
\hline Mean Importance & & & & & & \\
\hline B-Quality measures & $93,3 \mathrm{c}$ & 70,6 & 2 & $3,82 \mathrm{c}$ & 3,15 & 8 \\
\hline 1-Number of credit claims & 90,8 & 74,8 & 3 & $4,43 \mathrm{~d}$ & 3,94 & 1 \\
\hline 2-picking / shipping accuracy & $90,6 \mathrm{~d}$ & 73,7 & 4 & 4,20 & 4,17 & 5 \\
\hline 3-Shipping errors & $84,4 \mathrm{~b}$ & 35,0 & 7 & 4,21 & 3,79 & 4 \\
\hline $\begin{array}{l}\text { 4-Document / invoicing } \\
\text { accuracy }\end{array}$ & & & & & & \\
\hline 5-Order entry accuracy & $80,0 \mathrm{~b}$ & 45,0 & 8 & 4,19 & 4,00 & 6 \\
\hline 6-Over reliability & $70,0 \mathrm{~b}$ & 29,4 & 9 & 4,35 & 3,92 & 2 \\
\hline 7-Number of customer returns & 96,8 & 88,9 & 1 & 3,87 & 3,6 & 7 \\
\hline 8-Delivery consistency & 87,8 & 77,8 & 5 & 4,24 & 4,17 & 3 \\
\hline 9-Damage frequency & 87,5 & 75,00 & 6 & 3,80 & 3,56 & 9 \\
\hline Mean Importance & & & & 4,12 & & \\
\hline $\begin{array}{l}\text {.a Scale :1= unimportant ; }=\text { important } \\
\text {. b p } \leq 0,001 ; \text { c p } \leq 0,01 ; \mathrm{d} \leq 0,1\end{array}$ & & & & & \\
\hline B. Supply side & & & & & & \\
\hline
\end{tabular}

\section{B. Supply side}

TABLE V. Benchmarks the top third firms on the importance and information availability of supply side performance measures in the categories of cost and productivity. Both the first six cost measures and the first six productivity measures significantly distinguish the benchmarked top third firms from the bottom third firms on 
either greater importance or greater information availability. All twelve of these cost and productivity measures are basic performance measures. In contrast, more esoteric and sophisticated performance measures such as cost of returned goods, cost of service failures, and cost of customer segments do not significantly distinguish top third from bottom third firms.

Turning to the importance rankings of top third firms for cost in the far right column of TABLE V. total cost and cost trend analysis rank first and second, respectively. These measures are followed in importance by outbound freight cost, cost per unit, comparison of actual cost versus budget, and cost as a percentage of sales, in that order. It is informative to note that each of these first six highest ranked cost measures is a basic and relative measure that allows for easy comparison with a readily available standard or its own incorporated benchmark. For example, total cost typically has a comparative objective function of simultaneously minimizing the sun of several cost tradeoffs. Thus, minimizing total cost is relative to itself or to its previous calculation as a standard (i.e., as long as the first derivative of the cost function is less than zero). For productivity importance ranking in the bottom right section of TABLE V. a total productivity index is ranked first by top third firms. Followed by warehouse labor productivity, units shipped per employee, and comparison to historical standard. Again, these high rankings reflect basic and relative performance measures in that they have internal or easily available benchmarks. Similar to the previous customer service and quality results, total cost and total productivity index are total performance measures that are especially important to top third firms.

TABLE V. Availability and importance of supply sied performance measures for top third excellence index firms versus bottom third [1]

\begin{tabular}{|c|c|c|c|c|c|c|}
\hline \multirow{2}{*}{ Mesure de la performance } & \multicolumn{3}{|c|}{ Percent having Information Available } & \multicolumn{3}{|c|}{ Average Importance Rating a } \\
\hline & $\begin{array}{l}\text { Top Tiers } \\
\text { [\%] }\end{array}$ & $\begin{array}{l}\text { Tiers } \\
\text { inférieur [\%] }\end{array}$ & $\begin{array}{l}\text { Top Tiers } \\
\text { rang }\end{array}$ & $\begin{array}{l}\text { Top } \\
\text { Tiers }\end{array}$ & $\begin{array}{l}\text { Tiers } \\
\text { inférieur }\end{array}$ & $\begin{array}{l}\text { Top Tiers } \\
\text { rang }\end{array}$ \\
\hline 1- Outbound cost & 100,00 & 94,9 & 1 & $4,40 \mathrm{~b}$ & 3,67 & 3 \\
\hline 2- Cost as a percentage of sales & $96,8 \mathrm{~d}$ & 84,2 & 3 & $4,33 \mathrm{~d}$ & 3,95 & 6 \\
\hline 3- Direct labor & $96,5 \mathrm{~d}$ & 83,9 & 4 & 4,03 & 3,76 & 7 \\
\hline 4- Administrative cost & 93,6 & 84,1 & 6 & $3,70 \mathrm{~d}$ & 3,33 & 14 \\
\hline 5- Warehouse order processing & 87,5 & 80,2 & 8 & $3,90 \mathrm{c}$ & 3,31 & 9 \\
\hline 6- Inbound freight cost & 77,4 & 79,0 & 13 & $4,00 \mathrm{c}$ & 3,5 & 8 \\
\hline 7- Direct product profitablity & 62,5 & 36,8 & 14 & 3,81 & 3,79 & 10 \\
\hline 8- Cost of backorder & 33,3 & 27,8 & 17 & $3,71 \mathrm{c}$ & 3,18 & 13 \\
\hline $\begin{array}{l}\text { 9- Comparison of actual versus } \\
\text { budget }\end{array}$ & 98,5 & 96,5 & 2 & 4,34 & 4,40 & 5 \\
\hline 10 -Total cost & 93,8 & 95,2 & 5 & 4,56 & 4,35 & 1 \\
\hline 11- Cost trend analysis & 92,8 & 90,3 & 7 & 4,41 & 4,42 & 2 \\
\hline 12- Cost of damage & 87,5 & 80,1 & 9 & 3,55 & 3,26 & 15 \\
\hline 13- Inventory carrying cost & 86,7 & 73,7 & 10 & 3,79 & 3,39 & 11 \\
\hline 14- Cost per unit & 83,9 & 83,3 & 11 & 4,38 & 4,06 & 4 \\
\hline 15- Cost of returned goods & 81,3 & 75,2 & 12 & 3,45 & 3,17 & 17 \\
\hline 16- Cost of customer segments & 41,9 & 55,2 & 15 & 3,52 & 3,94 & 16 \\
\hline 17- Cost of service failure & 40,6 & 47,4 & 16 & 3,78 & 3,73 & 12 \\
\hline Mean importance & & & & 3,98 & & \\
\hline \multicolumn{7}{|l|}{ B-Productivity Measures } \\
\hline $\begin{array}{l}\text { 1- Warehouse labor } \\
\text { productivity }\end{array}$ & 90,6 & 79,9 & 1 & $4,13 \mathrm{~d}$ & 3,65 & 2 \\
\hline 2 Comparison to historical std. & 87,5 & 73,7 & 2 & $3,93 \mathrm{c}$ & 3,29 & 4 \\
\hline 3- Units shipped per employee & $83,8 \mathrm{~b}$ & 57,9 & 3 & 4,07 & 3,86 & 3 \\
\hline 4- Total productivity index & $78,1 \mathrm{c}$ & 57,6 & 4 & $4,15 \mathrm{c}$ & 3,57 & 1 \\
\hline 5- Equipment downtime & $65,6 \mathrm{~b}$ & 27,8 & 6 & $3,64 \mathrm{~b}$ & 2,92 & 7 \\
\hline 6- Order per salespereson & $50,2 \mathrm{c}$ & 55,6 & 9 & $3,00 \mathrm{c}$ & 3,54 & 9 \\
\hline 7- Unite per labor dollar & 67,7 & 57,8 & 5 & 3,6 & 3,77 & 8 \\
\hline 8- Order entry productivity & 65,6 & 52,9 & 7 & 3,69 & 3,29 & 5 \\
\hline 9- Transport labor productivty & 64,5 & 73,6 & 8 & 3,68 & 3,69 & 6 \\
\hline importance moyenne & & & & 3,76 & & \\
\hline
\end{tabular}

It is again worth comparing the importance rankings with the information availability rakings of the benchmarked top third firms. Analogous to the earlier reactive quality results, TABLE V. shows that some of the least important cost measures are tracked by a large percentage of the top third firms. Specifically, "cost of 
damage" is ranked fifteenth in importance and "cost of returned goods" is ranked seventeenth and last, yet both are available to more $80 \%$ of the top firms. Thus, similar to the previous reactive quality findings, these reactive or negative performance measures appear less important than "doing it right the first time," but apparently provide quite useful information to top firms regarding problem.

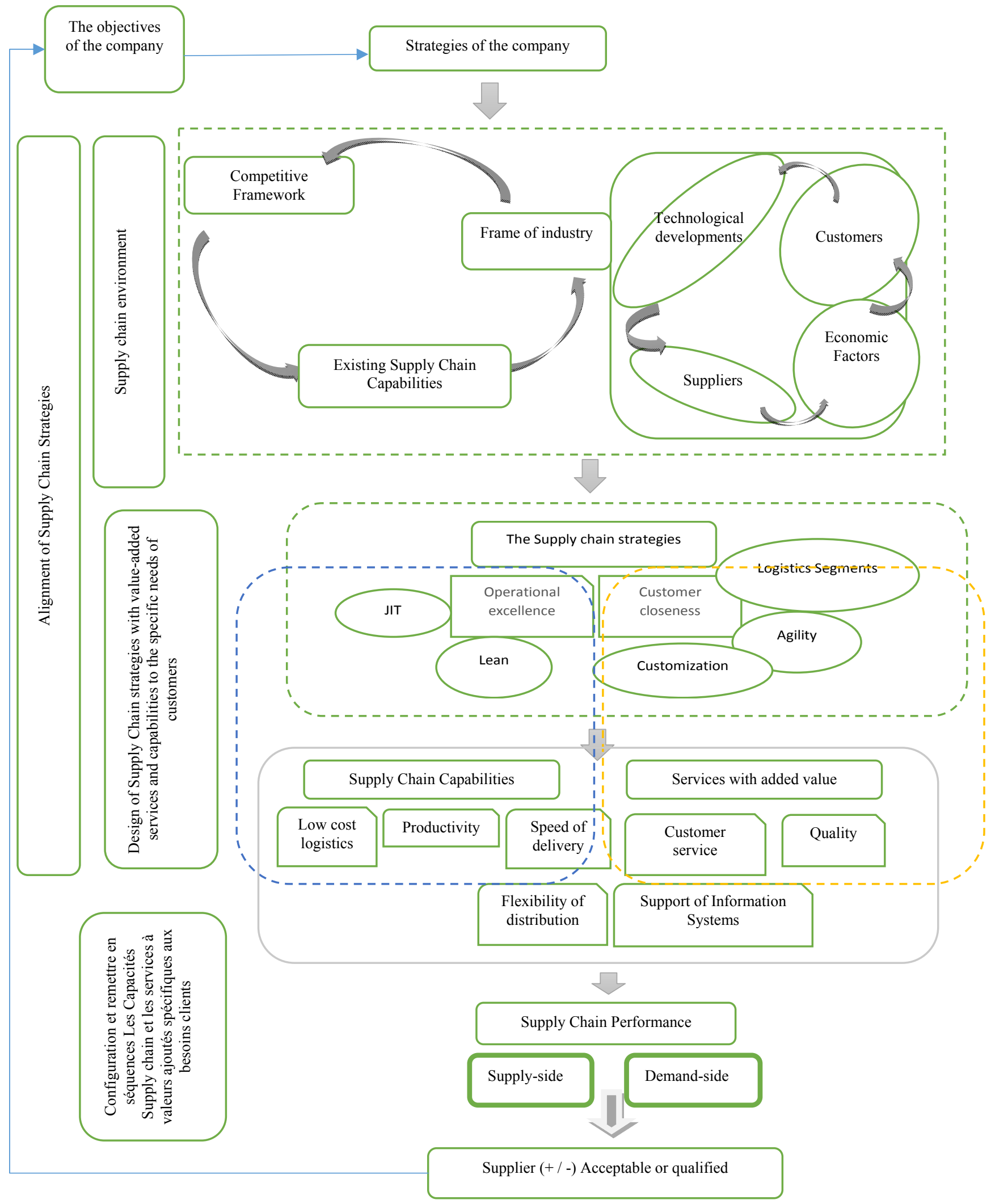

Fig. 1. The Under the model for the design of a strategy Supply Chain Aligned with the strategy of the company 


\section{CONCLUSION}

Supply chain strategy is an increasingly important topic in an environment of deregulation, inter-firm cooperation and partnerships, strategic alliances, and technological advancements. Similarly, a new model or supply chain strategies supported by particular capabilities and resulting in related performance is clearly gaining in interest to the practitioners. As such, strategic intent predict that there should be a value consistency or normative fit between supply chain strategies, capabilities, and performance: e.g., a demand focus on customer closeness or a supply focus on operational excellence. This focus becomes part of the competitive advantage of the supply chain that should foster member firm' success. Further, strategic intent recommends that once firms have developed minimum supply-side and demand-side capabilities to be order qualified, they should then concentrate on those capabilities and performance metrics that support their chosen value focus. To do other-wise would waste time and resources and would dilute the firms' message and image in the marketplace. . According to the survey results [1], the qualifiers' minimum order on the current performance are the elimination of waste, avoid damage and customer returns. À leur tour, d'autres capacités qui distinguent les meilleures des meilleures entreprises par rapport à d'autres sociétés dans cette étude peuvent être interprétées comme des ordres gagnants pour atteindre ces valeurs objectives. The order of significant demand oriented examples include services of added value and order of flexibility, While significant offer oriented examples include standardization of operations and low cost of logistics. The sub-model of the Fig. I has indeed found strong evidence of strategic intent between supply chain strategies, capabilities and performance. First, for excellent firms, a demand-side focus on customer service and proactive quality is more apparent and important at both the capability and performance levels that a supply-side focus on cost, productivity, distribution, and speed. Second, demand-side capabilities and demand-side performance are most strongly related to the firm excellence index. Third, demand-side capabilities are most strongly related to customer closeness strategies such as customized logistics and agility. In contrast, supply-side capabilities are most strongly related to operational excellence strategies such as time-based strategies e.g., Lean and JIT. Fourth, particular types of capabilities distinguish and support individual supply chain strategies. On the demand side, customer participation in strategy formulation distinguishes customization, while continuous interactions, collaborations, and communications with customers characterize agility. On the supply side, inventory velocity and supply synchronization distinguish time-based strategies, while minimum total cost in typifies Lean. In total, these findings support strategic intent across supply chain strategies, capabilities and performance.

In this context, the proper alignment of the supply chain with the company strategy is essential to ensure a high level of performance of the company. The sub-model "Designing a Supply Chain strategy aligned with the company's strategy" will be exploited in future work to design optimal supply chain strategies based on the Lean supply chain and finally, The overall model of the development of supply chain strategies by the implementation of concepts Lean manufacturing.

\section{REFERENCES}

[1] Edward A. Morash, Supply chain strategies, capabilities, and performance. Transportation Journal, pp 37, 2001

[2] Scanlon R., 2001, Aligning Product and supply chain Strategies in the mobile phone industry, B.S computer Science cornell University, Ithaca, NY.

[3] Hau L. Lee., 2002, Aligning Supply Chain Strategies with Product Uncertainties, Havard Business school,pp 16

[4] Godsell. J et al, 2006, Customer responsive supply chain strategy. An unnatural act? International Journal of Logistic: Research and Applications

[5] Marshall L. Fisher. 1997." What is the right supply chain for your Product? Havard Business Review

[6] Qi, Y., Boyer, K.K. \& Zhao, X. 2009. Supply chain strategy, product characteristics, and performance impact: Evidence from Chinese manufacturers. Decision Sciences Journal, 40(4): 667-95.

[7] Duarte, S. \& Machado, V.C. 2011. Manufacturing paradigms in supply chain management. International Journal of Management Science and Engineering Management, 6(5): 328-42.

[8] El-Tawy, N. \& Gallear, D. 2011. Leanness and agility as means for improving supply chains: A case study on Egypt. European, Mediterranean and Middle East Conference on Information Systems, 809-41.

[9] Lee, H.L. 2002. Aligning supply chain strategies with product uncertainties. California Management Review, 44: 105-119.

[10] Ismail, H.S., Sharifi, H. 2006. A balanced approach to building agile supply chains. International Journal of Physical Distribution and Logistics Management, 26(6) 431-44.

[11] Qi, Y., Zhao, X. \& Sheu, C. 2011. The impact of competitive strategy and supply chain strategy on business performance: The role of environmental uncertainty. Decision Sciences Journal, 42(2): 371-389.

[12] Ambe, I.M., Badenhorst-Weiss, J.A. 2011. South African automotive industry: trends and challenges in the supply chain. Journal of Contemporary Management, 8: 337-362.

[13] Sebastiao, H.J. \& Golicic, S.L. 2008. Supply Chain Strategy for Nascent Firms in Emerging Technology Markets. Journal of Business Logistics, 21(1): 75-91.

[14] Chopra, S. \& Meindl, P. 2010. Supply chain management: Strategy, planning and operation. Upper Saddle River, New Jersey: Pearson.

[15] Hull, B.Z. 2005. Are supply (driven) chains forgetting? The International Journal of Logistics Management, 16(2): 218-36.

\section{AUTHOR PROFILE}

Jaouad KAZMANE: Phd student in Industrial Technology at the faculty of science and technology of Fes

Abdelali ENNADI: Professor at the faculty of science and technology of Fes 